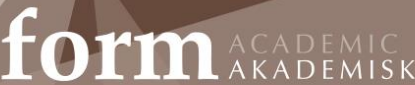

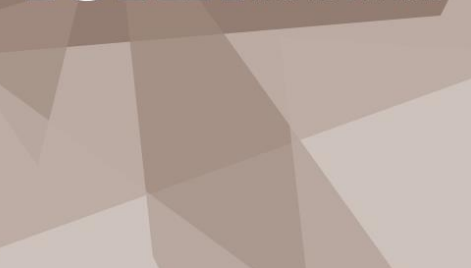

Anneli Palmsköld

Professor, PhD

Department of Conservation anneli.palmskold@conservation.gu.se

Vol I4, No 2 (2O2I)

\title{
Craft consumption and participatory consumerism
}

\begin{abstract}
How are crafters, in this case hand knitters active on social media, involved in participatory consumerism and prosumption? This is the main question asked in this article, that explores the creative relations between craft consumers and the commodities they are searching for in order to be able to craft and to create. By using affect theory, and focusing on aspects as raw materials, tools, instructions and craft processes, the study is an exploration of how crafters engage in material conditions by using them to realize ideas and fantasies in craft.
\end{abstract}

Keywords:

Craft and affect theory, participatory consumerism, prosumption, hand knitting

\section{INTRODUCTION}

Crafters who are continuously involved in making, remaking and transforming materials are consumers with a special way of considering and assessing the selection of goods they need to be able to create. They develop "creative relationships" with the goods they consume for these purposes (Vachhani, 2013: 93). The crafters' specific gaze is used to identify opportunities such as interesting materials to work with or unique forms and details that can be used, reused and inserted into new contexts (Palmsköld, 2013). The crafter can be understood as a conventional consumer, but one who engages in what is called "prosumption" or "participatory consumerism" (Knott 2013). These types of consumers are looking for goods that in different ways encourage and inspire further processes of crafting and making, goods that have the possibility to inspire the crafter to engage in creative processes. If the craft process is about what Tim Ingold calls "entanglement with material", the market is full of potential, opportunities and promises (Ingold, 2013: 22). The "creative relationships" between the crafter and the goods contain affective elements, as the interpretations of material and design are based on sensual experiences (Vachhani, 2013:93). By sensing, seeing, touching and listening it is possible to evaluate the qualities and possibilities of the material. The craft consumers can imagine what can be done and created through the use of their specific craft skills. 
This article is based on a study, published in Swedish, and here adapted to international readers (Palmsköld 2019). The empirical material is the same, however, the research questions are more directed towards the crafters' involvement in materials, and my own experiences as a researcher and practitioner has been emphasized. The article examines how crafters, in this case hand knitters active on social media, act as "prosumers" and how they develop "creative relationships" with the goods they buy. The crafters in focus are knitters who use Ravelry as a social platform for sharing, inspiring and discussing their craft (www.ravelry.com). Ravelry has been criticized for excluding minorities and for letting members speech in a hateful way about politics, when discussing hand knitting related issues. Like many social fora's that have grown in members, the community have had difficulties in managing to administrate and stop these kinds of expressions. The presentation of the website currently emphasizes that it is both inclusive and friendly (www.ravelry.com /2021-01-31). However, it is important to notice that craft, and especially textile craft, has long been related to politics and to political activities from the historical suffragette movement, to the contemporary social and political movement called "craftivism" (Literat and Markus 2018).

In the study, craft related aspects such as yarn (raw material), knitting needles and knitting supplies (tools), patterns (instructions) and projects (craft processes and their results) will be analyzed. The purpose is to contribute, through an empirical study of the contemporary culture of knitting, to the discussion on how craft consumption can work and how "creative relations" are developed between the crafters and the goods they consume and the meaning of crafters' "engagement with materials" (Ingold, 2013: 22). An important aspect is to reflect upon the crafter as a consumer, depending on different markets to be able to reach necessary raw material and supplies. This is crucial for crafters, and an important part of their work. Questions asked are: What is consumed and how? Which creative relationships arise in the process? How do crafters/ knitters describe themselves and the meaning of their involvement in different materials?

The study is part of the ethnological research tradition that deals with what people actually do in their everyday lives (Löfgren, 2014:77 and 84). In this case, it is about people's complex relationships with materials and objects - "material lore" (Wilson 2006) - and a focus rather on "how" people do, than on "why" (Löfgren, 2014:78). The study is about on how hand knitters are using social media to communicate about their craft, about craft processes and how to knit. The study is also a contribution to the craft science research, especially the auto ethnographical parts, when the researcher self is also a crafter and thereby uses his/ her specific knowledge to deepen the analysis of the processes (see eg Almevik, 2017; Westerlund, 2017; Eriksson, 2019). Here I use my more than 50 years long experience of practicing hand knitting, along with an extensive historical knowledge of knitting (JohanssonPalmsköld, 1989, 1990 and Palmsköld, 2009). Working as museum antiquarian (1990-2011), I have been curating exhibitions about hand knitting and sloyd, and I have also initiated a project that aimed to collect objects, archival material and books about hand knitting. As a member of Ravelry, I have been studying it as a scene for communication about hand knitting and used it as an inspiration for my own craft projects, but I have not been an active posting member.

This article starts with a discussion on the concepts of craft consumption and participatory consumerism. Another aspect that is discussed, is affect theory and how it can be used to understand the creative relationships that arise between a crafter and his or her materials. How crafts can be considered in terms of transformations of materials into things and what these processes can mean, is a question raised. The empirical section analyzes how contemporary hand knitters act as craft consumers, by analyzing presentations and discussions at the digital knit and crochet community Ravelry (www.ravelry.com /2019-04-09). Finally, it is discussed how craft consumption among contemporary knitters works and how creative relationships with materials are created and expressed in craft practices.

\section{Craft consumption and participatory consumerism}

Consumer practices that involve craft dimensions have been discussed in research and what has been called "craft consumption" has been identified as an important part of contemporary consumer culture (Campbell, 2005:27). This specific type of consumption is defined as an activity where people not only 
control the consumption process, but also add skill, knowledge, judgment, love and passion to their consumption, as has been assumed by traditional craftsperson to approach their work (ibid, 2005:27). The craft consumer transform goods and personifies them by using their own individual and personal creative ability (ibid, 2005:28). Usually it is about putting things together in a certain way to achieve an intended aesthetic whole, like dressing in vintage or retro clothes (ibid, 2005:34) or decorating their home with furniture and inventories of different ages and in varying styles. But it can also be about using goods as (raw) materials and parts in a craft process. The concept "prosumer" highlights consumer creativity and the agent of the consumers that lead them to engage in the objects and materials that the market offers and which can be used to produce something (Knott, 2013). "Prosumption" can be described as "participatory consumerism", which can take the form of "The designer-producer hands over a limited degree of productive power to the consumer." (ibid, 2013:53). Examples of goods intended for this form of prosuming are paint-by-number kits and IKEA's furniture (ibid, 2013). In focus here is a fairly controlled activity, where the consumers' creative activities are planned and controlled through the design of the goods and the instructions that come with it.

Consuming goods to transform or customize has been described with terms derived from the computer world, such as "hacker" and "plug-in" (von Busch, 2008: 59). Especially in relation to the growing second-hand market of goods, crafters and other "prosumers" by learning about objects and materials, have been able to build on them. This creative and affective relationship between the craft consumer and the goods on the second-hand market requires knowledge of styles and craftsmanship, and of craft techniques (Palmsköld, 2013 and 2018). When the craft consumer decides on an upcoming craft process, the goods must first be interpreted and evaluated. Questions to consider are for example: How can the product be used and what is possible to do with it? In some cases: Which parts are original, what is unique or authentic and worth preserving or starting from? What can be added?

Craft consumption can, however, also be about acquiring raw materials, tools, instructions and knowledge on how to master the craft process to achieve the intended result. In the contemporary hand knitting world, it is about finding yarns of the right size and quality for the project to be carried out, knitting needles of the right gauge and length, other supplies such as stitch markers or cable needles and a pattern to start from (unless the knitter make his/ her own design). In order to process the knitting afterwards, it may be about finding an underlay to block it on so that it gets the desired shape and size, but also to even out the surface and become smoother. The goods that the crafter is interested in can initiate a process, where their potential as a contribution in a making process is assessed. They affect the craft consumers to act, both by consuming but also by using the goods in their crafts (Clough \& Halley, 2007).

The products on the market work as active materials, which inspire ideas and fantasies about what they can become and be transformed into (Palmsköld, 2013; Ingold, 2013:21 and 28). How these creative relationships between the crafter and the goods works can be understood by means of affecttheoretical perspectives. In the anthology Sensitive Objects: Affect and Material Culture. the authors discuss what studies about the body, the senses and the atmosphere can bring to anthropological and ethnological research (Povrzanovic Frykman and Frykman, 2016). Three concepts that can describe affect are identified: intensity, readiness and potential (ibid, 2016:10). As affective experiences are personal and bodily, they can be difficult to describe and express in words according to the authors (ibid, 2016:11). Other concepts of interest is affective processes and affective potential (Brembeck and Sörum, 2017). Transferred to hand knitting, this can be about how different yarn qualities feels in the hands of the knitter, against the skin and the body, and also how the thread feels when it slides between the fingers. The information provided by the examination of the yarn quality, helps the crafter to discover its potential. Ideas can be raised about what it can be used for, and alternatively, if it is a suitable and desirable choice of yarn for a specific project. Even the visual experience plays a role and what colors and nuances are offered are important elements to consider in the process. What is available on the market is therefore crucial for what opportunities are offered to hand knitters, although there are also examples of those who control their own raw material by spinning and dyeing it. The raw material itself thus carries an affective potential in relation to the crafter as it can initiate creative processes. 
Within the contemporary hand knitting culture, social media are used to share and communicate craftrelated issues. In blogs, on Facebook, Youtube, Instagram and Pinterest it is possible to show craft processes and their result, to inspire others. Hand knitted products, raw material, instructions and knitting supplies can be bought and sold at Etsy, a global digital marketplace for creative and sometimes handmade products (www.etsy.com / 2020-11-06). The most important digital gathering place for hand knitters is Ravelry, which started in 2007. On the web page it states that:

Ravelry is an inclusive, friendly website for knitters, crocheters, spinners, weavers, and dyers. We are made up of millions of yarn lovers from all over the world. Ravelry provides a personal notebook for fiber artists to keep track of their projects, yarns \& fibers, tools, and pattern library, a rich database of patterns and yarns, and a community with thousands of forums and groups to connect with other Ravelers over any interest you could think of. (www.ravelry.com / 2021-01-31)

By registering as a member, you can log in and thus be part of the group. The main language used is English, although there are pages and descriptions in other languages. On the first page for logged in members, there are headings such as: "patterns", "yarns", "friends", "groups", "help", "forums" and a personal page that can be developed by the user. Under the headings, you can search for more information on, for example, design, specific yarn qualities and interesting designers. Through the web page it is possible to buy and share patterns, published by amateurs as well as professional designers. In addition to the fact that Ravelry inspire crafters, it is possible to conduct joint hand knitting projects in discussion threads, or to ask questions about uncertainties in craft procedures. Questions can be asked between knitters, and in some cases directly to designers, often it applies to how detailed parts in patterns and descriptions should be understood and interpreted.

\section{Hand knitters as craft consumers}

In the following, by using empirical examples, I will discuss four aspects of hand knitters' craft consumption: raw materials, tools, instructions, and craft processes (and their results). The examples represent important discussions about crafts-related challenges and problems, which require solutions to be able to carry out the project that the hand knitter is working on. A hand knitting project starts with an idea and with some form of instruction. This can be based on a designer's pattern, but it can also be based on the knitter's own design. To be able to implement the idea, adequate raw material and tools are required, but technical knowledge in knitting is also needed to be able to carry out and control the process up to the finished result.

Here it may be relevant to refer to an important difference between the crafter's entrance to his or her work: one is about crafters' who focus on the process, and the other on those who mainly care about the goal - the finished product (Lind, 2020:156ff). When it comes to hand knitting, it is in the first case a matter of carrying out projects that challenges the skills of the knitters, which means that the knitters have to make an effort and be concentrated in the process itself. In the second case, the knitters prefer projects that are quick to implement and which are completed within a reasonable time. To illustrate the differences, the gauge of the yarn and knitting needles are of importance: the thinner the yarn and the finer the knitting needles, the longer a project will take. If the craft process itself and the various procedures involved are complex (such as several colors and / or a complicated form) and contain more advanced techniques (such as, for example, lace, braids or crossed stitches), the project will take more time to finish. Another way to analyze the process is to explore the intentions of the individual knitter: is it about following a detailed instruction, or starting a project with an outer frame (finger mittens, socks or sweater with raglan cut) and see which direction it takes (Arantes, 2020).

\section{Raw material}

By clicking on the heading "Yarn" on Ravelry, opportunities open up to search for specific names of yarns, yarn companies and fibers. Among these are synthetic fibers such as acrylic, nylon and polyester, plant fibers such as bamboo, cotton and linen and animal fibers such as alpaca, cashmere and wool. Even odd fibers such as bison, camel and yak are present. Each yarn is presented on a separate page 
with information on quality, length and weight per skein, shades of color, texture and care. By clicking on links, it is possible to obtain additional information such as manufacturers, resellers, projects where the yarn has been used, user comments and images. The information is adapted both to the American and the European market, for example length measurements are given in yards and in meters.

For the trained hand knitter, the information about the yarns is important. It is, for example, possible to imagine how different materials feel to touch and work with, to see color shades and think out interesting combinations, and it is possible to calculate how much material is needed in specific projects. By studying images posted by users on their projects during the knitting process or when completed, it is possible to get inspiration for one's own crafting and for the choice of design, materials and colors.

In a Swedish context, the choice of which material to use for hand knitting, can be the result of ethical and moral considerations. The discussion about the use of natural materials or synthetic fibers often arises among the hand knitters. In the Facebook group Online Stickcafé, the issue was discussed about why some do not consider it "right" to knit in acrylic (www.facebook.com/groups/onlinestickcafe/ March 29, 2018 / 2019-04-08). The arguments against the use of acrylic yarn are, among other things, that plastic is bad for the environment, that it is dangerous especially for babies to inhale, that it is static, sweaty, dense, uncomfortable against the body and that it heats worse than wool. Those who use acrylic yarn find it easy to knit with, and a comfortable material that keeps color and shape. Several use the material as a criticism of contemporary sheep keeping, they may also have allergies to wool and lanolin and consider wool itching. Acrylic is considered to be easy to handle, as it can be washed without the risk of shrinking, it is also a cheaper material than wool. Several respond in the discussion towards a loud tone, with emotionally charged arguments from both sides. Above all, the criticism is that it seems as if there is a "right" choice (wool) and a "wrong" choice (acrylic), when it should be up to each and every knitter to choose which material to use and when.

\section{Tools}

The technique of hand knitting has historically attracted economically poor groups of people as it was a way to transform yarn into surface (fabric) that did not require any major investment or any further space for tools and bodily movements (Palmsköld, 2005). To be able to knit, the only supplies needed is access to materials that could be spun to yarn and four or five knitting needles to knit round shapes that could form mittens, socks, caps or sweaters. Hand knitting could be performed in many different situations, in social contexts and on foot. In geographical places where the population was earning their living by hand knitting, such as in the southern parts of the region Halland in Sweden, it was important that the needles were blunt to avoid wounds on the fingers (Johansson-Palmsköld, 1989 and 1990). By knitting around, the garments needed no major work effort to be ready to use or sell. It was often enough to fasten the threads and to treat the garment so that it shrunk and became tight and durable.

In the 19th century's emerging handicraft culture, textile crafting became a way of perform the contemporary idea of femininity (Svensson and Waldén, 2005, Palmsköld, 2017). Patterns and descriptions began to spread, showing hand knitting done on two knitting needles, back and forth and often with a visible right and a wrong side. This was the case with the exception of mittens, socks and caps that were still knitted around. During the 20th century, the point of departure for hand knitters was still to create parts such as sleaves, collars, edges and front and back pieces that were assembled and joined together, in the same way as when sewing garments. In some cases, the descriptions consisted of paper patterns that indicated the shape and frames of each part. Many Contemporary hand knitters today want to avoid mounting and therefore some designers work from this parameter, for example by making cardigans and sweaters knitted from the top down in a certain order, or button edges on cardigans which are incorporated in the knitting so that they do not need to be sewn in afterwards.

In a contemporary context, there has been extensive product development towards more customized and user-friendly supplies and tools. Previously, it was a certain focus on that pointed knitting needles could lead to wounds on the fingers, today questions about how routine hand knitters avoid wrist and shoulder pain are discussed. An often-recommended solution, is to use circular needles, 
so that the weight of the growing work is distributed more evenly. An innovation in the actual craft process is not to use double pointed needles at all, but instead a long circular cable where smaller work is divided into two parts, and the soft part of the cable forms a loop. The technique is called magic loop and it is perceived as easier to work with, than to handle double pointed needles. Other innovations are interchangeable circular needles that are sold in sets with cables and tops that can be replaced depending on the size each project require. For those who work with several parallel projects, the cables can retain the stitches and the tops are unscrewed and moved to another knitting. An additional novelty is the cuboid shaped needles, which are considered to give a better grip.

Under the heading "Forum" on Ravelry there is a group that focuses on discussing "tools \& equipment" (www.ravelry.com/discuss/tools/topics/ 2019-04-08). Members can post questions and ask for help and recommendations. A frequently asked question here, and in other social media, is about where to find the best and most sustainable quality of wooden knitting needles. Wooden needles are appreciated because they are considered as comfortable to hold and easy to use. Though, several members express problems with the fact that these are easily broken off. In another thread yarn bowls, which are used to keep the yarn in place during the knitting process, are discussed. A functional one should be steady and the yarn thread should run smoothly. It cannot hook up, as the evenly rhythm in the hand knitting process is broken. There are yarn bowls available in various materials such as ceramics, plastic and in the form of small baskets. Further discussions apply to equipment for blocking the finished projects. It may apply to the best underlay that a project can be pinched on, or where wires to stretch out knitted shawls are available.

\section{Instructions}

For members of Ravelry the ability to share patterns with others are important. Amateurs and professional designers publish their patterns, either for free or for sale. Some designers have thus come to be celebrities in the world of hand knitting, attracting many followers who knit their own versions of the patterns that are shared. Some of these "superstars" have been able to develop their own businesses based on sales of designs, publishing of pattern books, building of own platforms in social media, workshops, and collaboration with yarn sellers and manufacturers. One example of such designer is Kate Davies, who is represented by 286 different patterns on Ravelry (www.ravelry.com /2020-11-09). In February 2010, a pattern was published on a sweater called "owls" that has links to 9163 projects and is mentioned in 642 blog posts (www.ravelry.com / 2020-11-09). The sweater is knitted in one color, it has a round yoke with a pattern of knitted cables that forms a row of owls with attached buttons that form pairs of eyes. Another popular project is the sweater "Paper Dolls" which was published in June 2013 and has links to 1313 projects and mentioned in 133 blog posts (www.ravelry.com / 2020-11-09). This sweater also has a round yoke with a multicolor pattern in the form of people standing lined up together. Kate Davies has through her company Kate Davies Design published a book on knitted yokes that has been printed in several editions, including this pattern (Davies, 2016).

An important part of the hand knitting process for those who follow printed instructions, is to correctly interpret the descriptions of the different procedures. Hand knitting is based on mathematical principles (Arantes, 2020). First, a test piece should be knit in the yarn and needles to be used, and in the technique on which the pattern is based. The number of stitches and the number of rows on a given surface must correspond with the indications on the pattern, in order to achieve the correct dimensions. Decreases and increases are made gradually. Some instructions on Ravelry are rather ideas about how the result can be, others are extremely detailed mentioning each individual stitch through a project. At Ravelry, designers have a possibility to post their own pages where their followers can turn their questions. Sometimes this leads to discussions between the hand knitters, sometimes the designer in question responds directly. An example of this interaction between knitters and the designer is Heidi Kirrmaier's site on Ravelry, where she continuously answers questions about how her pattern instructions should be interpreted and whether the knitter who asks for help has translated it correctly in the making. Heidi Kirrmaier's instructions belong to the more detailed, her works are ingeniously designed and shapes are created through evenly distributed extensions of stitches that provide wide 
and shortened rows to create rounded shapes. One of the most popular patterns is a cardigan named "Vitamin D", which has links to 5085 projects and is mentioned in 376 blog entries (www.ravelry.com / 2020-11-09). Although the pattern is very detailed, many knitters still have personalized it. Some by using several colors instead of one, some by lengthening the cardigan.

\section{Craft processes and results}

Many members use Ravelry to post images and comments on their projects, some also provide insights into parts of the craft process in the form of a diary that shows different stages on the way towards completion. The presentation includes information on which choices of yarns the hand knitter has made, sometimes the choices coincide with the designer's recommendations and sometimes other qualities are used. Skilled hand knitters have a stash of yarns that easily can be activated. In some cases, the size of the knitting needles is also indicated. If colors and shades are not commented on in text, the published images reveal whether and how other combinations have been chosen than those recommended. The images of the various procedures are taken to show the actual work and which stage in the craft process. It is usually the hand knitters' themselves who takes photographs and if they are visible, it is as models and users of the finished projects.

A designer with many followers is Stephen West. His most popular design like "Boneyard Shawl" has 9315 links to projects, the cap "Windschief" has 8232 and the shawl "Daybreak" has 7112 (www.ravelry.com / 2020-11-09). Stephen West is approaching design from an artistic perspective and his projects is characterized by many colors and unexpected forms. His instructions are detailed and often easy to follow. A follower who has knitted the shawl "Daybreak" has posted five pictures, and she writes on her page about the craft process:

\section{3/30 Started!}

4/3: Not enough contrast between color $A$ and color B...hate to do it but I am going to start over with a new color $A$

4/6: SO.WORTH.IT. (www.ravelry.com/projects/liveloveyarn/daybreak /2019-04-08)

The first image shows the yarns that have been used and the starting faze of the project, which is carried out with the help of a circular needle and stitch markers showing the middle of the piece. The second commentary in the description is followed by an image that illustrates the lack of contrast between the bottom color and the pattern colors. The solution to the problem is shown in the next image, where the original bottom color has been replaced by a darker shade. The last two images show the finished shawl in its entirety and how it looks when it has been draped around the neck of the knitter.

Another hand knitter has published seven images to illustrate the process when she knitted the same shawl. One of them shows how the finished shawl has been blocked, with many needles attached tightly along the edge (www.ravelry.com/projects/moderndaygypsy/daybreak-2 / 2019-04-09). Another hand knitter describes how she has allowed the project to rest for a few days to pick it up again and find out that there is a missing stitch in a specific part of the knitting. She has solved this by adding a stitch on a wrong side row, and notes that she must count stitches at certain intervals (www.ravelry.com/projects/Maryteddie/daybreak-2 / 2019-04-09). In a post, a knitter puts out tips for others. It is about a way to bind off stitches which makes the edge straight and does not roll, and also a link to a blog with tips on how shawls can be blocked to reach the best results (www.ravelry.com/projects/indoorkitty/daybreak / 2019-04-09).

\section{DISCUSSION: CRAFT CONSUMPTION AND PARTICIPATORY CONSUMERISM}

Craft consumption is a basic activity for crafters, which provides them with necessary supplies to be able to craft. These supplies are for example raw materials, tools, and in some cases instructions. Crafters, as for example hand knitters, are also in need of discussing the craft process, creative demands and technical aspects in order to be inspired and to develop their own craft skills. Through craft consumption, or prosumption, the consumer becomes a producer, involved in what has been called 
"participatory consumerism". The supplies that are consumed, demands participation from the crafter in order to be activated and used in a transforming process. Apart from creativity and imagination, a bond is formed between the crafter and the supplies: a creative relationship that inspires to develop more ideas and to craft. This relationship is based on the affective potential that the supplies can have. By using affect theory, the sensory aspects of the creative relationship are pointed out. The crafter uses his/ her own senses to assess the potential that lye in for example using different raw material or tools.

The discussions on social media concerning the use of acrylic or wool yarn, is an example of an opposite situation, also involving ethical and political values. Those who refuse to use one yarn quality, does not develop a creative relationship towards the raw material. They can, however, give a vivid description on the negative affective potential the material has and why. When it comes to instructions and patterns, some hand knitters tend to see them as something to start with and then they feel free to make their own adaptions and personal adjustments. Others follow the patterns thoroughly, seeking help when needed by asking other hand knitters or the designer for help. Craft processes and the results of them, are often published on Ravelry. By taking images and discussing creative and technical demands and solutions, other hand knitters can be affected and inspired. These processes make it possible to increase the skills and the know how within the hand knitting community.

\section{CONCLUSION}

Social media, as for example Ravelry, enables affective processes and the establishment of creative relationships between practitioners and materials. Through the images that are published, experienced hand knitters can by seeing, also imagine how raw material feels to touch and to work with. They are able distinguish different yarn qualities. Thus, they can understand how the yarns work in the craft process and assess which yarn to use for specific projects. Furthermore, they can assess whether colors and shades match what they want. User comments and discussions are helpful in the assessments, and many hand knitters and members of Ravelry are happy to express their affective experiences in words and images. This contradicts the notion that these are difficult to express and shows the crafters need to find ways to communicate sensory experiences with like-minded people.

Hand knitters devote to a large extent to "prosumption" and "participatory consumerism" and through Ravelry and other social media, worlds of possibilities are opened with regard to the supply of materials, tools, instructions and processes of making. It is possible to get help from others to solve technical problems and to interpret patterns and it is possible to create your personal pages and showcase your own creative ability. The person who is part of the hand knitting community has good opportunities to develop as a crafter together with others. 


\section{REFERENCES}

Almevik, G. (ed.) (2017). Hantverksvetenskap. Hantverkslaboratoriet, Göteborgs universitet. http://hdl.handle.net/2077/52386

Arantes, L. (2020). Unraveling Knitting: Form Creation, Relationality, and the Temporality of Materials. The Journal of American Folklore,133(528), 193-204. https://doi.org/10.5406/jamerfolk.133.528.0193

Brembeck, H. (2015). Nostalgi som affektivt redskap på retro- och vintagemarknaden. Kulturella Perspektiv: Svensk etnologisk tidskrift, 24(3-4), 3-13.

Brembeck, H. \& N. Sörum (2017). Assembling nostalgia: devices for affective captation on the re:heritage market, International Journal of Heritage Studies, 23(6), 556-574. https://doi.org/10.1080/13527258.2017.1300928

Busch, O. von (2008) Fashion-able. Hacktivism and Engaged Fashion Design. [Doctoral Theses, Göteborgs universitet]. http://hdl.handle.net/2077/17941

Campbell, C. (2005). The Craft Consumer: Culture, Craft and Consumption in a Postmodern Society. Journal of Consumer Culture, 5(1), 23-42. https://doi.org/10.1177/1469540505049843

Clough, P. Ticineto \& J. O'Malley Halley (2007). The Affective Turn. Theorizing the Social. Duke University Press. https://doi.org/10.1215/9780822389606

Davies, K. (2016). Yokes: eleven signature designs, with stories of the sweater that changed the shape of modern knitting (Third edition). Kate Davies Designs.

Eriksson, J. (2019). Kalkbruk: krympsprickor och historisk utveckling av material, metoder och förhållningsätt. [Doctoral thesis. University of Gothenburg]. http://hdl.handle.net/2077/58552

Ingold, T. (2013). Making. Anthropology, Archaeology, Art and Architecture. Routledge. https://doi.org/10.4324/9780203559055

Johansson-Palmsköld, A. (1989). Tre halländska bingetröjor. In A. W. Mårtensson \& B. Hammar (red.) Kulturen, 1989, pp. 53-62. Kulturhistoriska föreningen för södra Sverige.

Johansson-Palmsköld, A. (1990). Avsalustickningen i södra Halland: från vardagsvara till hemslöjdsprodukt. Etnologiska institutionen, Lunds Universitet. https://gup.ub.gu.se/file/206782

Knott, S. (2013). Design in the Age of Prosumption. The Craft of Design after the Object. Design and Culture 5(1), 45-47. https://doi.org/10.2752/175470813X13491105785587

Lind, M. (2020). Handspinning Tradition in the United States: Traditionalization and Revival. The Journal of American Folklore,133(528), 142-164. https://doi.org/10.5406/jamerfolk.133.528.0142

Literat I. \& S. Markus (2020) 'Crafting a way forward': online participation, craftivism and civic engagement in Ravelry's Pussyhat Project group, Information, Communication \& Society, 23(10), 1411-1426. https://doi.org/10.1080/1369118X.2019.1573910

Löfgren, O. (2014). The Black Box of Everyday Life. Entanglements of Stuff, Affects and Activities. Cultural Analysis, 13, 77-98. https://www.ocf.berkeley.edu/ culturalanalysis/volume13/pdf/Lofgren.pdf

Palmsköld, A. (2009). En historia om stickning. In: Stickning. Ett hantverk att utveckla, (pp. 212-223). Hemslöjdens förlag.

Palmsköld, A. (2013). Textilt återbruk. Om materiellt och kulturellt slitage. Gidlunds förlag.

Palmsköld, A. (2015). Reusing Textiles. Culture Unbound, 7(1), 31-43. https://doi.org/10.3384/cu.2000.1525.157131

Palmsköld, A. (2017). Den omoraliska virkningen. In (ed.) Jönsson, L.-E. Politiska projekt, osäkra kulturarv (pp. 2355). Lund Studies in Arts and Cultural Sciences.

Palmsköld, A. (2018). Vintage, retro, shabby chic: concepts used on the Re:heritage market. Ethnologia Scandinavica, 48, 38-54.

Palmsköld, A. (2019). Hantverkares sätt att konsumera. In: Peterson Mclntyre et al. (eds.) Konsumtionskultur: innebörder och praktiker (pp. 132-147). Makadam. 
Povrzanovic Frykman, M. \& Frykman, J. (2016). Sensitive Objects: Affect and Material Culture. Kriterium. https://doi.org/10.21525/kriterium.6

Svensson, B. \& L. Waldén (eds.) (2005). Den feminina textilen: makt och mönster. Nordiska museets förlag.

Vachhani, S. J. (2013). (Re)creating Objects from the Past - Affect, Tactility and Everyday Creativity. Management \& Organizational History, 8(1), 91-104. https://doi.org/10.1080/17449359.2013.750052

Westerlund, T. (2017). Trädgårdsmästarens förökningsmetoder: dokumentation av hantverkskunskap. [Diss. Göteborg: Göteborgs universitet]. https://gupea.ub.gu.se/handle/2077/52089

Wilson, W. A. (2006). Documenting Folklore. In ed Jill Terry Rydi. The Marrow of Human Experience: Essays on Folklore (pp. 81-103). Utah State University Press. 